\title{
Reduced Expression of Prostacyclin Synthase and Nitric Oxide Synthase in Subcutaneous Arteries of Type 2 Diabetic Patients
}

\author{
Siti Safiah Mokhtar, ${ }^{1}$ Paul M. Vanhoutte, ${ }^{2}$ Susan W.S. Leung, ${ }^{2}$ Mohd Imran Yusof, ${ }^{3}$ \\ Wan Azman Wan Sulaiman, ${ }^{4}$ Arman Zaharil Mat Saad, ${ }^{4}$ Rapeah Suppian ${ }^{5}$ and \\ Aida Hanum Ghulam Rasool ${ }^{1}$
}

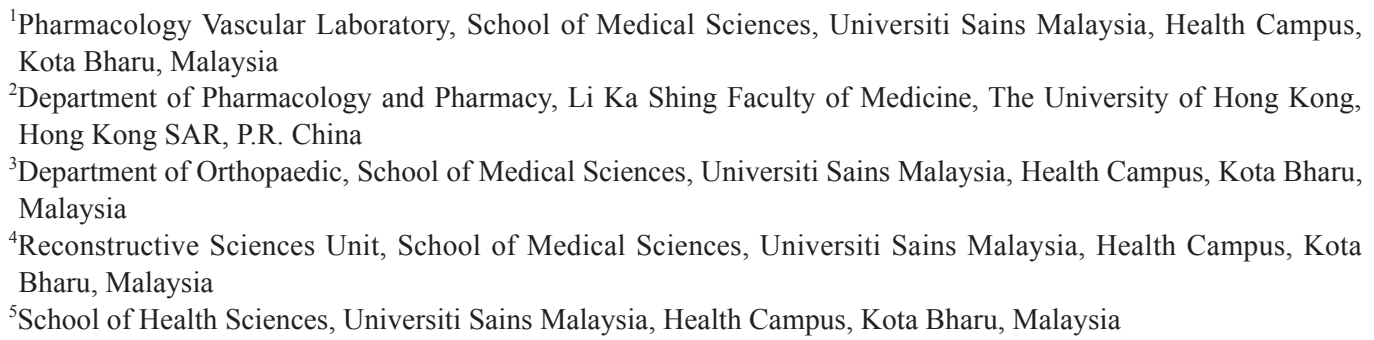

Diabetic endothelial dysfunction is characterized by impaired endothelium-dependent relaxation. In this study, we measured the expression of endothelial nitric oxide synthase (eNOS), cyclooxygenase-1 (COX1), cyclooxygenase-2 (COX-2), prostacyclin synthase (PGIS), and prostacyclin receptor (IP) in subcutaneous arteries of type-2 diabetic and non-diabetic patients. Subcutaneous arteries were dissected from tissues from seven diabetics ( 4 males and 3 females) and seven non-diabetics ( 5 males and 2 females) aged between 18 to 65 years, who underwent lower limb surgical procedures. Diabetics had higher fasting blood glucose compared to non-diabetics, but there were no differences in blood pressure, body mass index and age. Patients were excluded if they had uncontrolled hypertension, previous myocardial infarction, coronary heart disease, renal or hepatic failure and tumor. The relative expression levels of eNOS, COX-1, COX-2, PGIS and IP receptor were determined by Western blotting analysis, normalized with the $\beta$-actin level. Increased expression of COX-2 was observed in subcutaneous arteries of diabetics compared to non-diabetics, whereas the expression levels of eNOS and PGIS were significantly lower in diabetics. There were no significant differences in expression levels of COX-1 and IP receptor between the two groups. Immunohistochemical study of subcutaneous arteries showed that the intensities of eNOS and PGIS staining were lower in diabetics, with higher COX-2 staining. In conclusion, type-2 diabetes is associated with higher COX-2 expression, but lower eNOS and PGIS expression in subcutaneous arteries. These alterations may lead to impaired endothelium-dependent vasodilatation, and thus these proteins may be potential targets for protection against the microvascular complications of diabetes.

Keywords: diabetes; endothelial dysfunction; microcirculation; nitric oxide synthase; prostacyclin synthase Tohoku J. Exp. Med., 2013 November, 231 (3), 217-222. C 2013 Tohoku University Medical Press

\section{Introduction}

It has been estimated that 285 million (6.4\%) people worldwide were afflicted with diabetes mellitus in 2010, and that diabetes would affect 439 million (7.7\%) adults by 2030 (Shaw et al. 2010). Micro and macrovasculopathy are the major complications of diabetes and thus cardiovascular disorders (CVD) account for up to $80 \%$ of premature mortalities due to diabetes (Winer and Sowers 2004).

The endothelium, a monolayer of cells lining and cov- ering the internal surface of blood vessels, plays a crucial role in regulating vascular tone by releasing endotheliumderived contracting and relaxing factors. Imbalance in the production of these factors is a characteristic of endothelial dysfunction, one key event in the development of microvascular complications in human and animal models of diabetes (Pieper 1998; De Vriese et al. 2000; Matsumoto et al. 2005). Indeed, endothelium-dependent vasodilatation is impaired in arterioles of humans with type-2 diabetes (Georgescu et al. 2011; Kizhakekuttu et al. 2012).

Received July 4, 2013; revised and accepted October 18, 2013. Published online November 13, 2013; doi: 10.1620/tjem.231.217.

Correspondence: Aida Hanum Ghulam Rasool, Department of Pharmacology, School of Medical Sciences, Universiti Sains Malaysia,

Health Campus, Kota Bharu 16150, Malaysia.

e-mail: aida@kb.usm.my 
Nitric oxide (NO) and prostacyclin $\left(\mathrm{PGI}_{2}\right)$ are two major endothelium-derived relaxing factors. NO is synthesized from L-arginine, in the presence of oxygen and nicotinamide adenine dinucleotide phosphate (NADPH) in a reaction catalyzed by NO synthase (NOS). Three NOS isoforms are expressed in mammalian cells: neuronal NOS (nNOS), endothelial NOS (eNOS), and inducible NOS (iNOS) (Felaco et al. 2001). Of those, eNOS is expressed constitutively in endothelial cells; NO produced by eNOS is essential for the regulation of vascular tone (Duda et al. 2004). Blunted NO-mediated relaxations have been reported in coronary (Belmadani et al. 2008; Gao et al. 2008) and mesenteric arteries (Lagaud et al. 2001) from diabetic $(\mathrm{db} / \mathrm{db})$ mice. These observations may be due to the decreased expression of eNOS in the small arteries of diabetics.

Cyclooxygenase (COX) transforms arachidonic acid into prostaglandin endoperoxides $\left(\mathrm{PGH}_{2}\right)$. $\mathrm{PGH}_{2}$ is converted further into $\mathrm{PGI}_{2}$ by prostacyclin synthase (PGIS), into thromboxane $\mathrm{A}_{2}\left(\mathrm{TXA}_{2}\right)$ by $\mathrm{TXA}_{2}$ synthase and into other prostaglandins by the respective synthases (Zou et al. 2004). PGI $_{2}$ stimulates prostacyclin receptors (IP receptor) in vascular smooth muscles causing relaxation under physiological conditions (Linton and Fazio 2008). Both $\mathrm{PGH}_{2}$ and $\mathrm{TXA}_{2}$ oppose the action of $\mathrm{PGI}_{2}$ by activation of the thromboxane receptors (TP receptor) in smooth muscles causing vasoconstriction (Vanhoutte 2011).

Two isoforms of COX have been identified in blood vessels. COX-1 is constitutively expressed in a wide variety of tissues and participates in physiological responses, whereas COX-2 is an inducible enzyme. In coronary arterioles of humans with diabetes mellitus the expression of vascular COX-2 protein is increased compared to non-diabetics (Szerafin et al. 2006). COX-2 is also widely expressed in atherosclerotic plaques and arterial walls of patients with atherosclerosis (Baker et al. 1999). The expression levels of both COX-1 and COX-2 proteins are increased in the femoral arteries of diabetic rats (Shi and Vanhoutte 2008).

There is a lack of information on the expression levels of COX-1, PGIS and IP receptor proteins in the microcirculation of diabetic patients. Thus, the present study aims to determine the expression levels of eNOS, COX-1, COX-2, PGIS and IP receptor proteins in subcutaneous arteries of diabetic patients compared to non-diabetic controls. Information gained may help to elucidate the roles of these proteins in the development of endothelial dysfunction in the human diabetic microcirculation (Szerafin et al. 2006; Georgescu et al. 2011).

\section{Materials and Methods}

\section{Patient Characteristics}

This study was approved by the Human Ethical Committee of Universiti Sains Malaysia; work conducted in this study conformed to the provisions of the Declaration of Helsinki. All of the patients gave their informed consent to participate in this study, which was con- ducted at the Universiti Sains Malaysia Hospital. Subcutaneous tissues were obtained from patients who underwent lower limb surgical procedures such as wound debridement, amputations, fracture stabilization and skin grafting. Specimens from patients who were operated on for any tumors were excluded. Subjects consisted of seven patients with type- 2 diabetes mellitus ( 4 males and 3 females) while the controls consisted of seven non-diabetic subjects ( 5 males and 2 females). All patients were between 18 to 65 years of age. Patients were excluded if they had uncontrolled hypertension, previous myocardial infarction, coronary heart disease and renal or hepatic failure. Evaluation of patients consisted of a physical examination, determination of body mass index (BMI) and measurements of systolic (SBP) and diastolic (DBP) blood pressures. Blood was collected to analyze the fasting blood glucose (FBG).

\section{Protein preparation and Western blot analysis}

Subcutaneous tissues were transported to the laboratory in ice cold physiological saline solution (PSS). They were dissected and homogenized in the lysis buffer $(\mathrm{NaCl} 150 \mathrm{mM}$, Tris $50 \mathrm{mM}$, Triton-X $1 \%$, sodium dioxycholate $10 \%$, sodium dodecyl sulfate (SDS) $0.1 \%$, ethylenediaminetetraacetic acid $(1 \mathrm{mM})$ and a protease inhibitor cocktail $0.05 \%$ (Sigma Chemical Co., St Louis, MO, USA). Samples were then centrifuged at $3,000 \mathrm{~g}$ for 20 minutes at $4{ }^{\circ} \mathrm{C}$, and the supernatants were collected. Protein concentrations were determined using the Bradford assay. In all immunoblot experiments, the same amount of protein was loaded in each lane of $10 \%$ SDSpolyacrylamide gel. After electrophoresis, proteins were electrotransferred to polyvinylidene difluoride (PVDF) Immobilon membranes (Millipore Corp., Billerica, MA, USA) and incubated for two hours at room temperature with primary antibodies against eNOS (1:15,000 Abcam, Cambridge, UK), COX-1 (1:10,000; Abcam), COX-2 (1:10,000; Abcam), PGIS (1:10,000; Abcam) and IP receptors $(1: 10,000 ;$ Abcam). The same blot was stripped and then reprobed with other proteins. To normalize for the amount of proteins, $\beta$-actin was used as a loading control (1:10,000; Sigma Chemical Co.). Membranes were then incubated in horseradish peroxidase (HRP)conjugated polyclonal secondary antibody, (1:10,000; Abcam) in blocking buffer for one hour at room temperature. Membranes were incubated with an Immobilon Western chemiluminescent HRP substrate (Millipore Corp.) for five minutes and exposed to CL-Xposure films (Thermo Fisher Scientific, Rockford, IL, USA). The intensity of protein bands representing the amount of proteins was measured with Image $J$ software (http://rsb.info.nih.gov/ij/). The relative protein presence of eNOS, COX-1, COX-2, PGIS or IP receptors was expressed as percentage of the total amount of protein (indicated by the intensity of protein band for $\beta$-actin) in the same patient sample (Sugimura et al. 2010; Lee and Lee 2011).

\section{Immunohistochemistry}

Subcutaneous skin samples were fixed and processed for 18 hours with 4\% paraformaldehyde solution in PBS at pH 7.4 and embedded in paraffin. Samples were cut to $5 \mu \mathrm{m}$ thick slices, and collected on poly-L-lysine slides; they underwent de-paraffinization in xylene and rehydration in graded alcohol solutions. Endogenous peroxidases were blocked by $0.3 \%$ hydrogen peroxide and antigen retrieval was performed in citrate buffer, $\mathrm{pH}$ 6.0. Primary antibodies against eNOS (1:100), COX-1 (1:200), COX-2 (1:200), PGIS (1:100) and the IP receptor $(1: 100)$ were diluted with PBS-T and incubated on slides for two hours at room temperature. After having been rinsed 
two times for five minutes with PBS-T solution, the slides were incubated with secondary antibody conjugated to HRP (1:200) for one hour at room temperature. The immunoreactions were visualized using 3, 3'diamino-benzidine-tetrahydrochloride substrate (DAB) (Roche, Mannheim, Germany).

\section{Data Analysis}

The Statistical Package for Social Sciences software for Windows, Version 20.0 (SPSS Inc. 2011) was used to analyze the data. In all cases, $n$ refers to the number of patients. Differences between the two groups were assessed by independent $t$-test. All data were expressed as the mean \pm standard deviation. Differences were considered significant at $p<0.05$.

\section{Results}

\section{Patient characteristics}

The diabetic patients were slightly older than the nondiabetic controls; however the difference was not statistically significant (Table 1). The FBG concentration was significantly higher in the diabetic patients (Table 1). BMI and BP did not differ between the groups. One patient in the diabetic group was treated for hypertension and hyperlipidemia. All patients in the diabetic group took hypoglycemic drugs. None of the patients in the non-diabetic control group was taking any regular medication.

\section{Western blotting}

Western blot analysis demonstrated that the expression levels of eNOS and PGIS were significantly lower in the subcutaneous arteries from diabetic patients compared to non-diabetic controls (Fig. 1A and B): eNOS expression, diabetic $13.7 \pm 3.8 \%$ vs. non-diabetic $26.9 \pm 1.8 \%(p<$ $0.001)$; and PGIS, diabetic $14.2 \pm 4.3 \%$ vs. non-diabetic $21.6 \pm 5.1 \%(p=0.013)$. COX-2 expression was significantly higher in the subcutaneous arteries from diabetic patients compared to non-diabetic controls (diabetic $23.5 \pm$ $5.7 \%$ vs. non-diabetic $11.4 \pm 2.9 \%, p<0.001$ ). The expression levels of COX-1 and IP receptor proteins were not significantly different in the subcutaneous arteries from both groups: COX-1, non-diabetic $12.6 \pm 2.6 \%$ vs. diabetic 14.2 $\pm 2.6 \%(p=0.264)$; and IP receptor, non-diabetic $8.5 \pm$ $1.6 \%$ vs. diabetic $7.66 \pm 1.3 \%(p=0.308)$.

\section{Immunohistochemistry}

Immunohistochemical analysis demonstrated that the intensities of immunoreactive eNOS and PGIS protein were higher in the subcutaneous arteries of the non-diabetic controls compared to the diabetic patients (Fig. 2). The intensity of immunoreactive COX-2 protein was higher in the arteries of diabetic patients compared to the non-diabetic controls. There were no significant differences in the COX-1 and IP proteins staining between the groups.

\section{Discussion}

The results from this study show that the expression of eNOS and PGIS proteins is decreased, but that of the COX-2 protein is increased in the subcutaneous arteries of the diabetic patients compared to the non-diabetic controls.

The decreased eNOS protein expression observed in the subcutaneous arteries of diabetic patients may be related to the high plasma glucose levels, often associated with diabetes. The eNOS protein expression in cultured human coronary arterial and aortic endothelial cells incubated in media containing a high glucose concentration $(25 \mathrm{mM})$ is reduced compared to that in the lower glucose concentration (5.5 mM) (Ding et al. 2000; Srinivasan et al. 2004). In cultured human aortic endothelial cells, hyperglycemia increased mitochondrial production of reactive oxygen species (ROS). Mitochondrial ROS, in turn, activate the transcription factor activator protein (AP-1) to bind to DNA. This binding inhibits the transcription of the eNOS gene, thus resulting in the reduction of eNOS protein expression (Srinivasan et al. 2004). Reduction in eNOS protein expression in diabetes may lead to the loss of vasodilator responses. This conclusion is supported by the reduced endothelium-dependent vasodilatation observed in subcutaneous arterioles of patients with type-2 diabetes (Georgescu et al. 2011). This reduction was associated with decreased eNOS protein expression and reduced endothelial NO pro-

Table 1. Patient Characteristics.

\begin{tabular}{lccc}
\hline \multicolumn{1}{c}{ Characteristics } & $\begin{array}{c}\text { Non-Diabetic } \\
(n=7)\end{array}$ & $\begin{array}{c}\text { Diabetic } \\
(n=7)\end{array}$ & $p$ value \\
\hline Sex (Male/Female) & $5 / 2$ & $4 / 3$ & \\
Age (year) & $39 \pm 12.7$ & $49 \pm 4.8$ & 0.110 \\
SBP (mmHg) & $129 \pm 5.5$ & $129 \pm 8.5$ & 0.520 \\
DBP (mmHg) & $81 \pm 4.0$ & $75 \pm 10.9$ & 0.224 \\
Weight $(\mathrm{kg})$ & $67 \pm 6.4$ & $68 \pm 7.6$ & 0.748 \\
Height $(\mathrm{cm})$ & $162 \pm 7.6$ & $159 \pm 5.5$ & 0.367 \\
BMI $\left(\mathrm{kg} / \mathrm{m}^{2}\right)$ & $25 \pm 1.5$ & $26 \pm 1.6$ & 0.277 \\
FBG $(\mathrm{mmol} / \mathrm{l})$ & $4.8 \pm 0.5$ & $9.7 \pm 2.5^{*}$ & 0.002 \\
\hline
\end{tabular}

Data are expressed as mean \pm S.D. ${ }^{*} p<0.05$, diabetic patients compared to non-diabetic controls. SBP, systolic blood pressure; DBP, diastolic blood pressure; BMI, body mass Index; FBG, fasting blood glucose. 
A

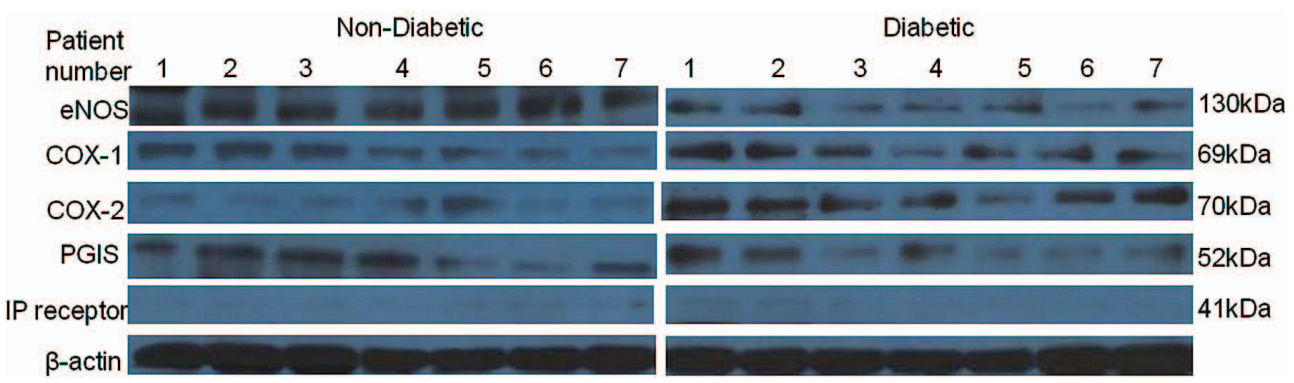

B

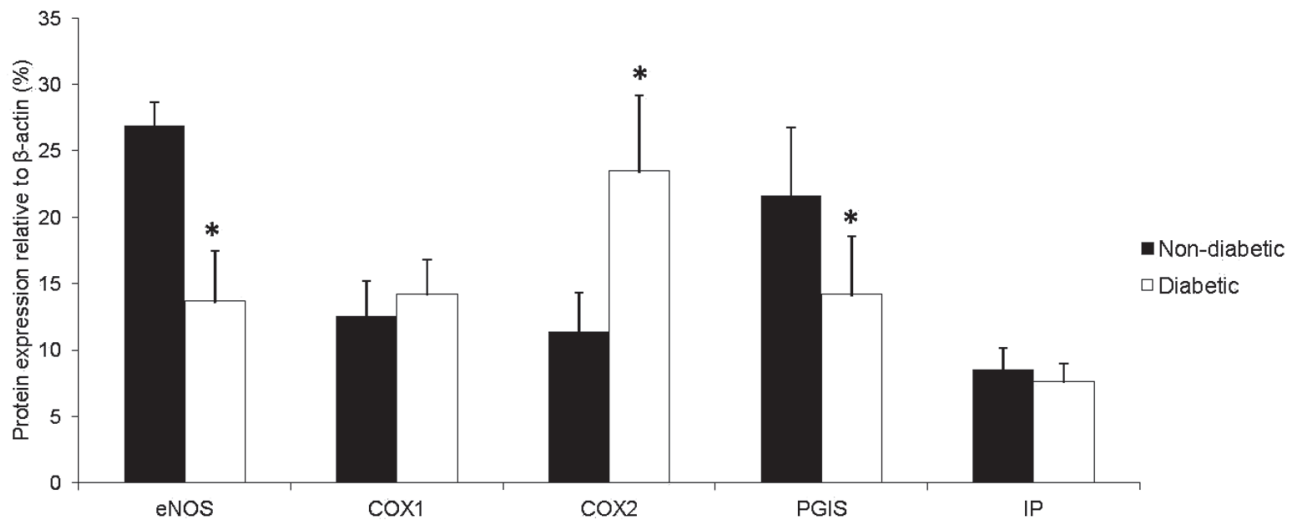

Fig. 1. Western blot analysis of proteins in the subcutaneous arteries of non-diabetic controls and diabetic patients.

(A) Western blot demonstrated the expression of eNOS, COX-1, COX-2, PGIS and IP receptor proteins from seven diabetic and seven non-diabetic controls. (B) Graphical representation of the data, normalized to $\beta$-actin, is shown as the mean percentage \pm S.D. $(n=7)$.

$* P<0.05$ diabetic patients compared to non-diabetic controls.

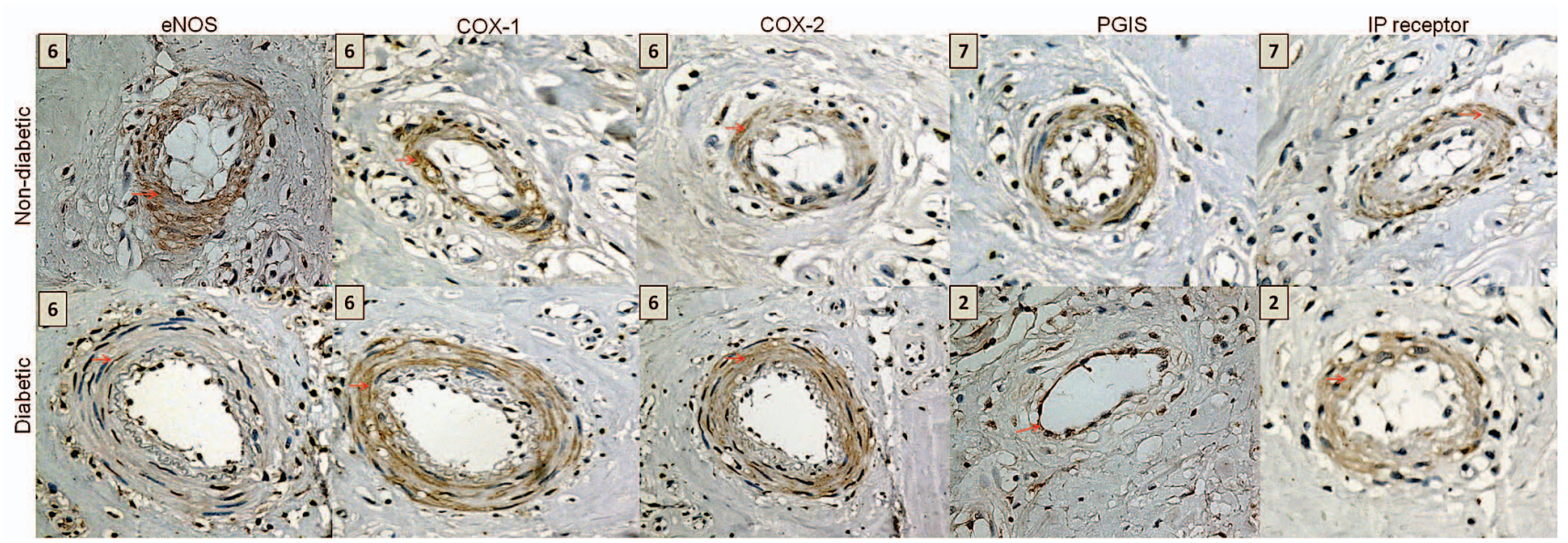

Fig. 2. Immunohistochemical analysis of proteins in subcutaneous arteries of non-diabetic controls and diabetic patients. Immunohistochemical staining of eNOS, COX-1, COX-2, PGIS and IP receptor proteins in the subcutaneous arteries of representative diabetic patients and non-diabetic controls. The number shown in the box at the top left side of each tissue section indentifies the patient from which the subcutaneous arteries were obtained (which corresponds to patient numbers on the top of the Western blot in Fig. 1A). Brown staining indicates expression of respective proteins (red arrows). Magnification $20 \times$.

duction (Georgescu et al. 2011) and altered mitochondrial function (Kizhakekuttu et al. 2012).

The present immunohistochemical study and Western blotting analysis demonstrates increased COX-2 protein expression in the small arteries of diabetic patients. These findings are in accordance with an immunohistochemical study performed on coronary arterioles of diabetic patients compared to healthy controls (Szerafin et al. 2006). Increased COX-2 protein expression may result from the increased production of oxidative stress in diabetes. In human aortic endothelial cells cultured in high glucose medium, the production of superoxide anions was increased and this was associated with increased COX-2 protein expression (Cosentino et al. 2003). Superoxide anion pro- 
duction was also increased in the coronary arterioles of diabetic patients (Guzik et al. 2002). Increased expression of COX-2 protein (Bagi et al. 2005; Guo et al. 2005; Shi et al. 2007) and increased production of superoxide anions (Winer and Sowers 2004; Shi et al. 2007; Shi and Vanhoutte 2008) also occur in vascular tissues of different animal models of diabetes mellitus. Increased COX-2 protein expression may also result from low-grade inflammation associated with diabetes (Szerafin et al. 2006). Proinflammatory cytokines such as tumor necrosis factor- $\alpha$ and interleukin- $1 \alpha / \beta$ can enhance the transcription of the COX-2 gene and increases the protein level of COX-2 (Mitchell et al. 1995; Bagi et al. 2006).

In the coronary arterioles of diabetic patients, up-regulation of COX-2 protein is associated with increased vasodilatation most likely due to an increased production of dilator prostaglandins (Szerafin et al. 2006). This may serve as a compensatory mechanism to maintain an adequate blood supply to the cardiac tissue of diabetic patients whose coronary blood vessels may be narrowed or disturbed by the disease process (Szerafin et al. 2006). While a similar compensatory up-regulation of COX-2 protein expression and activity opposing endothelial dysfunction was observed in the mesenteric vascular bed of mice with type-1 diabetes (Nacci et al. 2009), in mice with type-2 diabetes, the up-regulation of COX-2 enhances the synthesis of the vasoconstrictors $\mathrm{PGH}_{2}$ and $\mathrm{TXA}_{2}$ in the aorta (Guo et al. 2005) and skeletal muscle resistance arteries (Bagi et al. 2005).

Although $\mathrm{PGI}_{2}$ as a rule is a vasodilator and an antiaggregating agent, depending on the circumstances, $\mathrm{PGI}_{2}$ can also act as an endothelium-derived contracting factor (Feletou et al. 2011; Vanhoutte 2011). In the aorta of spontaneously hypertensive rats (SHR), endothelium-dependent contractions most likely involve the action of $\mathrm{PGI}_{2}$ stimulating TP receptors (Gluais et al. 2005, 2006; Feletou et al. 2009). The absence of relaxation in response to $\mathrm{PGI}_{2}$ has been attributed to an early dysfunction of IP receptors in vascular smooth muscles in this hypertensive rat model (Numaguchi et al. 1999; Feletou et al. 2011). The present study shows the availability of IP receptors for the action of $\mathrm{PGI}_{2}$ in subcutaneous arteries of both diabetic patients and non-diabetic controls. Indeed, no difference was found in the IP receptor protein presence between the two groups. Although there were no changes in the expression of the IP receptor protein in diabetic patients, the present results do not rule out differences in responsiveness of these receptors to the action of $\mathrm{PGI}_{2}$ at the level of the microcirculation.

No information seems available as regards to the expression of PGIS protein in human subcutaneous arteries. In the present study, this expression was higher in non-diabetic controls compared to diabetic patients. One possible mechanism, by which PGIS protein expression is decreased in diabetes mellitus, is through the action of peroxynitrite (Souza et al. 2000). Indeed, exposure of endothelial cells to high glucose concentration increases the release of superox- ide anions $\left(\mathrm{O}_{2}{ }^{-}\right)$(Zou et al. 2002). Peroxynitrite is a potent oxidant formed by the reaction of $\mathrm{O}_{2}{ }^{--}$and NO. It reduces the expression of PGIS protein in endothelial cells (Cooke and Davidge 2002). It also inactivates PGIS at concentrations as low as $50 \mathrm{nM}$ through a tyrosine-nitration dependent mechanism (Zou et al. 2002, 2004). Nitration of tyrosine residues in certain proteins such as PGIS results in proteolytic degradation of the protein (Souza et al. 2000). Reduction of PGIS protein activity and/or expression results in the accumulation of its precursor, $\mathrm{PGH}_{2}$, which activates their receptors (TP receptor) in vascular smooth muscles causing vasoconstriction (Zou et al. 2002; Feletou et al. 2011; Vanhoutte 2011).

In conclusion, type- 2 diabetes mellitus is associated with higher COX-2 protein expression but lower eNOS and PGIS protein expression in human subcutaneous arteries.

\section{Acknowledgements}

This study was supported by the Universiti Sains Malaysia Research University Grant 1001/PPSP/812085. We thank Malaysian Ministry of Higher Education for providing a scholarship to Siti Safiah Mokhtar.

\section{Conflict of Interest}

The authors declare no conflict of interest in this study.

\section{References}

Bagi, Z., Erdei, N., Papp, Z., Edes, I. \& Koller, A. (2006) Up-regulation of vascular cyclooxygenase- 2 in diabetes mellitus. Pharmacol. Rep., 58, 52-56.

Bagi, Z., Erdei, N., Toth, A., Li, W., Hintze, T.H., Koller, A. \& Kaley, G. (2005) Type 2 diabetic mice have increased arteriolar tone and blood pressure: enhanced release of COX2-derived constrictor prostaglandins. Arterioscler. Thromb. Vasc. Biol., 25, 1610-1616.

Baker, C.S., Hall, R.J., Evans, T.J., Pomerance, A., Maclouf, J., Creminon, C., Yacoub, M.H. \& Polak, J.M. (1999) Cyclooxygenase-2 is widely expressed in atherosclerotic lesions affecting native and transplanted human coronary arteries and colocalizes with inducible nitric oxide synthase and nitrotyrosine particularly in macrophages. Arterioscler. Thromb. Vasc. Biol., 19, 646-655.

Belmadani, S., Palen, D.I., Gonzalez-Villalobos, R.A., Boulares, H.A. \& Matrougui, K. (2008) Elevated epidermal growth factor receptor phosphorylation induces resistance artery dysfunction in diabetic db/db mice. Diabetes, 57, 1629-1637.

Cooke, C.L. \& Davidge, S.T. (2002) Peroxynitrite increases iNOS through NF- $\kappa \mathrm{B}$ and decreases prostacyclin synthase in endothelial cells. Am. J. Physiol. Cell Physiol., 282, C395-402.

Cosentino, F., Eto, M., De Paolis, P., van der Loo, B., Bachschmid, M., Ullrich, V., Kouroedov, A., Delli Gatti, C., Joch, H., Volpe, M. \& Luscher, T.F. (2003) High glucose causes upregulation of cyclooxygenase- 2 and alters prostanoid profile in human endothelial cells: role of protein kinase $\mathrm{C}$ and reactive oxygen species. Circulation, 107, 1017-1023.

De Vriese, A.S., Verbeuren, T.J., Van de Voorde, J., Lameire, N.H. \& Vanhoutte, P.M. (2000) Endothelial dysfunction in diabetes. Br. J. Pharmacol., 130, 963-974.

Ding, Y., Vaziri, N.D., Coulson, R., Kamanna, V.S. \& Roh, D.D. (2000) Effects of simulated hyperglycemia, insulin, and glucagon on endothelial nitric oxide synthase expression. Am. J. Physiol. Endocrinol. Metab., 279, E11-17.

Duda, D.G., Fukumura, D. \& Jain, R.K. (2004) Role of eNOS in 
neovascularization: NO for endothelial progenitor cells. Trends Mol. Med., 10, 143-145.

Felaco, M., Grilli, A., De Lutiis, M.A., Patruno, A., Libertini, N., Taccardi, A.A., Di Napoli, P., Di Giulio, C., Barbacane, R. \& Conti, P. (2001) Endothelial nitric oxide synthase (eNOS) expression and localization in healthy and diabetic rat hearts. Ann. Clin. Lab. Sci., 31, 179-186.

Feletou, M., Huang, Y. \& Vanhoutte, P.M. (2011) Endotheliummediated control of vascular tone: COX-1 and COX-2 products. Br. J. Pharmacol., 164, 894-912.

Feletou, M., Verbeuren, T.J. \& Vanhoutte, P.M. (2009) Endothelium-dependent contractions in SHR: a tale of prostanoid TP and IP receptors. Br. J. Pharmacol., 156, 563-574.

Gao, X., Zhang, H., Schmidt, A.M. \& Zhang, C. (2008) AGE/ RAGE produces endothelial dysfunction in coronary arterioles in type 2 diabetic mice. Am. J. Physiol. Heart Circ. Physiol., 295, H491-498.

Georgescu, A., Popov, D., Constantin, A., Nemecz, M., Alexandru, N., Cochior, D. \& Tudor, A. (2011) Dysfunction of human subcutaneous fat arterioles in obesity alone or obesity associated with Type 2 diabetes. Clin. Sci. (Lond.), 120, 463-472.

Gluais, P., Lonchampt, M., Morrow, J.D., Vanhoutte, P.M. \& Feletou, M. (2005) Acetylcholine-induced endotheliumdependent contractions in the SHR aorta: the Janus face of prostacyclin. Br. J. Pharmacol., 146, 834-845.

Gluais, P., Paysant, J., Badier-Commander, C., Verbeuren, T., Vanhoutte, P.M. \& Feletou, M. (2006) In SHR aorta, calcium ionophore A-23187 releases prostacyclin and thromboxane A2 as endothelium-derived contracting factors. Am. J. Physiol. Heart Circ. Physiol., 291, H2255-2264.

Guo, Z., Su, W., Allen, S., Pang, H., Daugherty, A., Smart, E. \& Gong, M.C. (2005) COX-2 up-regulation and vascular smooth muscle contractile hyperreactivity in spontaneous diabetic $\mathrm{db} / \mathrm{db}$ mice. Cardiovasc. Res., 67, 723-735.

Guzik, T.J., Mussa, S., Gastaldi, D., Sadowski, J., Ratnatunga, C., Pillai, R. \& Channon, K.M. (2002) Mechanisms of increased vascular superoxide production in human diabetes mellitus: role of NAD $(\mathrm{P}) \mathrm{H}$ oxidase and endothelial nitric oxide synthase. Circulation, 105, 1656-1662.

Kizhakekuttu, T.J., Wang, J., Dharmashankar, K., Ying, R., Gutterman, D.D., Vita, J.A. \& Widlansky, M.E. (2012) Adverse alterations in mitochondrial function contribute to type 2 diabetes mellitus-related endothelial dysfunction in humans. Arterioscler. Thromb. Vasc. Biol., 32, 2531-2539.

Lagaud, G.J., Masih-Khan, E., Kai, S., van Breemen, C. \& Dube, G.P. (2001) Influence of type II diabetes on arterial tone and endothelial function in murine mesenteric resistance arteries. J. Vasc. Res., 38, 578-589.

Lee, J.D. \& Lee, M.H. (2011) Increased expression of hypoxiainducible factor- $1 \alpha$ and vascular endothelial growth factor associated with glomerulation formation in patients with interstitial cystitis. Urology, 78, e11-15.

Linton, M.F. \& Fazio, S. (2008) Cyclooxygenase products and atherosclerosis. Drug Discov. Today Ther. Strateg., 5, 25-36.

Matsumoto, T., Kobayashi, T., Wakabayashi, K. \& Kamata, K. (2005) Cilostazol improves endothelium-derived hyperpolarizing factor-type relaxation in mesenteric arteries from diabetic rats. Am. J. Physiol. Heart Circ. Physiol., 289, H1933-1940.

Mitchell, J.A., Larkin, S. \& Williams, T.J. (1995) Cyclooxy- genase-2: regulation and relevance in inflammation. Biochem. Pharmacol., 50, 1535-1542.

Nacci, C., Tarquinio, M., De Benedictis, L., Mauro, A., Zigrino, A., Carratu, M.R., Quon, M.J. \& Montagnani, M. (2009) Endothelial dysfunction in mice with streptozotocin-induced type 1 diabetes is opposed by compensatory overexpression of cyclooxygenase-2 in the vasculature. Endocrinology, 150, 849-861.

Numaguchi, Y., Harada, M., Osanai, H., Hayashi, K., Toki, Y., Okumura, K., Ito, T. \& Hayakawa, T. (1999) Altered gene expression of prostacyclin synthase and prostacyclin receptor in the thoracic aorta of spontaneously hypertensive rats. Cardiovasc. Res., 41, 682-688.

Pieper, G.M. (1998) Review of alterations in endothelial nitric oxide production in diabetes: protective role of arginine on endothelial dysfunction. Hypertension, 31, 1047-1060.

Shaw, J.E., Sicree, R.A. \& Zimmet, P.Z. (2010) Global estimates of the prevalence of diabetes for 2010 and 2030. Diabetes Res. Clin. Pract., 87, 4-14.

Shi, Y., So, K.F., Man, R.Y. \& Vanhoutte, P.M. (2007) Oxygenderived free radicals mediate endothelium-dependent contractions in femoral arteries of rats with streptozotocin-induced diabetes. Br. J. Pharmacol., 152, 1033-1041.

Shi, Y. \& Vanhoutte, P.M. (2008) Oxidative stress and COX cause hyper-responsiveness in vascular smooth muscle of the femoral artery from diabetic rats. Br. J. Pharmacol., 154, 639-651.

Souza, J.M., Choi, I., Chen, Q., Weisse, M., Daikhin, E., Yudkoff, M., Obin, M., Ara, J., Horwitz, J. \& Ischiropoulos, H. (2000) Proteolytic degradation of tyrosine nitrated proteins. Arch. Biochem. Biophys., 380, 360-366.

Srinivasan, S., Hatley, M.E., Bolick, D.T., Palmer, L.A., Edelstein, D., Brownlee, M. \& Hedrick, C.C. (2004) Hyperglycaemiainduced superoxide production decreases eNOS expression via AP-1 activation in aortic endothelial cells. Diabetologia, 47, 1727-1734.

Sugimura, K., Fukumoto, Y., Nawata, J., Wang, H., Onoue, N., Tada, T., Shirato, K. \& Shimokawa, H. (2010) Hypertension promotes phosphorylation of focal adhesion kinase and proline-rich tyrosine kinase 2 in rats: implication for the pathogenesis of hypertensive vascular disease. Tohoku J. Exp. Med., 222, 201-210.

Szerafin, T., Erdei, N., Fulop, T., Pasztor, E.T., Edes, I., Koller, A. \& Bagi, Z. (2006) Increased cyclooxygenase-2 expression and prostaglandin-mediated dilation in coronary arterioles of patients with diabetes mellitus. Circ. Res., 99, e12-17.

Vanhoutte, P.M. (2011) Endothelium-dependent contractions in hypertension: when prostacyclin becomes ugly. Hypertension, 57, 526-531.

Winer, N. \& Sowers, J.R. (2004) Epidemiology of diabetes. J. Clin. Pharmacol., 44, 397-405.

Zou, M.H., Cohen, R. \& Ullrich, V. (2004) Peroxynitrite and vascular endothelial dysfunction in diabetes mellitus. Endothelium, 11, 89-97.

Zou, M.H., Shi, C. \& Cohen, R.A. (2002) High glucose via peroxynitrite causes tyrosine nitration and inactivation of prostacyclin synthase that is associated with thromboxane/ prostaglandin $\mathrm{H}(2)$ receptor-mediated apoptosis and adhesion molecule expression in cultured human aortic endothelial cells. Diabetes, 51, 198-203. 